\title{
Ángel Ferrant. \\ El anhelo de las influencias pedagógicas
}

\section{Ángel Ferrant. The longing of the pedagogic influences}

\author{
IgnACIO AsEnJo FernÁNDEZ \\ Universidad Complutense de Madrid \\ iasenjo@art.ucm.es
}

Recibido: 10 de julio de 2011

Aprobado: 7 de marzo de 2012

\begin{abstract}
Resumen
El escultor Ángel Ferrant fue un hombre preocupado por la enseñanza del arte y su renovación, alcanzando la fama de renovador de la pedagogía artística en España. Su tarea pedagógica es tan intensa como poco conocida. Redactó varios escritos sobre reformismo pedagógico, fue asimismo autor de programas de formación artística y, durante la Guerra Civil española, formó parte activa de la Comisión de expertos creada por el gobierno de la Segunda República española para reorganizar las Escuelas Superiores de Bellas Artes. Ferrant siguió de cerca las tendencias pedagógicas más importantes de su tiempo. Estudió y analizó las obras de los grandes educadores y sintió afinidad por ellas. De sus lecturas extrajo un amplio espectro de anotaciones. La influencia de las obras de estos pedagogos fue notable y condicionó su trayectoria docente.
\end{abstract}

Palabras clave: Ángel Ferrant, Educación artística, Influencias pedagógicas, Notas transcritas.

Asenjo Fernández, I. (2013): Ángel Ferrant. El anhelo de las influencias pedagógicas. Arte, Individuo y Sociedad, 25(1) 11-29

\begin{abstract}
The sculptor Ángel Ferrant was a man worried about art teaching and its renovation, becoming famous for being a reformer of the artistic pedagogic in Spain. His pedagogical task is so intense as a stranger. He wrote several works on pedagogic reform, he was also an author of programs of artistic formation and, during the Spanish Civil War, he was an active member of the Commission of experts created for the government of the Second Republic in order to reorganize the Fine Art schools. Ferrant followed closely the most important pedagogic trends of his time. He studied and analyzed the works of the big educators and felt affinity for them. He extracted a wide spectrum of annotations from his readings. The influence of the works of these pedagogues was notable and determined his educational path.
\end{abstract}

Key Words: Ángel Ferrant, Art Education, Pedagogic Influences, Transcribed notes.

Asenjo Fernández, I. (2013): Ángel Ferrant. The longing of the pedagogic influences. Arte, Individuo y Sociedad, 25(1) 11-29

Sumario: 1. Introducción, 2. Epítome de las influencias, 3. Paradigmas educativos, 4. Conclusiones. Referencias. Documentos citados. 


\section{Introducción}

La historia de la Educación Artística y su desarrollo están ligados a variables contextuales y espacio-temporales. Cuestiones como la concepción del Arte y su aprendizaje, las posiciones teóricas sobre su función, las corrientes de pensamiento, los intereses de cada época y valores dominantes, pueden explicar este desarrollo en cada momento histórico. Las diferentes teorías, corrientes y posiciones teóricoprácticas, algunas de las cuales derivan tanto del campo de la pedagogía como de la psicología, han marcado el desarrollo pasado de la Educación Artística. Por su parte, el avance de diferentes ciencias como la biología, la sociología o la psiquiatría, han contribuido a ampliar dicho desarrollo. La renovación comienza en 1762, cuando Jean-Jacques Rousseau (1712-1778) publica su programa para la educación general del niño, defendiendo la necesidad de incluir el dibujo entre las prioridades de la educación del "nuevo ciudadano", junto con la lectura, la escritura y las matemáticas. Aunque sus innovaciones no se ponen en práctica hasta los primeros años del siglo XIX con la llegada de modernas pedagogías, la dinámica individualista de algunos hombres y mujeres de distintos países hará progresar la reforma social a través de la educación. Estos mentores que, preocupados por la mejora de la enseñanza, adoptan actitudes críticas respecto de las concepciones educativas tradicionales de su época, recibirán más tarde elogios, respeto y consideración social.

Buena parte de las modernas teorías artístico-pedagógicas de los siglos XIX y XX aboga por una didáctica experimental, enraizada en las vanguardias artísticas del momento. El estudio de los modelos estéticos emergentes permite diseñar técnicas, materiales y procedimientos con los que desarticular los modelos tradicionales de enseñanza. Todo ello incluye el análisis de los métodos de enseñanza artística, la crítica pedagógica, el estudio de los cambios metodológicos y el examen de los factores sociales que determinan los comportamientos artísticos de los miembros de cada sociedad. Los modernos modelos pedagógicos contribuyen a la aparición de conceptos y posibilidades completamente nuevos de la creación. Las renovaciones surgen con fines educativos de la infancia o de la formación industrial de los adolescentes. El aprovechamiento del potencial imaginativo y de la intuición de cada individuo es objeto de las nuevas pedagogías. Los métodos doctrinarios son desplazados en favor de fórmulas pedagógicas que sirvan a la exploración de la intencionalidad artística y de la creatividad, principalmente de los niños, así pues, los hábitos académicos de enseñanza artística basados en la copia de modelos son abolidos en favor de fórmulas de iniciación al trabajo artístico asentadas en el cultivo de la invención y el análisis de formas. La mayoría de estos métodos, por su carga crítica y erudita, no tiene éxito en su época, a no ser en círculos restringidos; sin embargo, algunos planes logran un éxito considerable.

Uno de los herederos de los principios de las modernas pedagogías es el escultor madrileño Ángel Ferrant (1890-1961), a quien no le son ajenas las influencias de las corrientes y tendencias pedagógicas más importantes de su tiempo. Su vocación docente acompaña continuamente a la creativa, y así se demuestra a lo largo de su trayectoria. Con gran experiencia en el ámbito docente comienza su actividad profesional como ayudante meritorio en la Sección $2^{\text {a }}$ de la Escuela de Artes y Oficios de Madrid desde el año 1914 hasta 1918, pasando por la de La Coruña de 1918 a 
1920, como Profesor titular de Término, y por Barcelona, de 1920 a 1933, en la Escuela de Artes y Oficios y Bellas Artes. A sus 43 años volverá a su ciudad natal, retomando la actividad docente a finales del curso escolar de 1933 a 1934 hasta su jubilación en 1954.

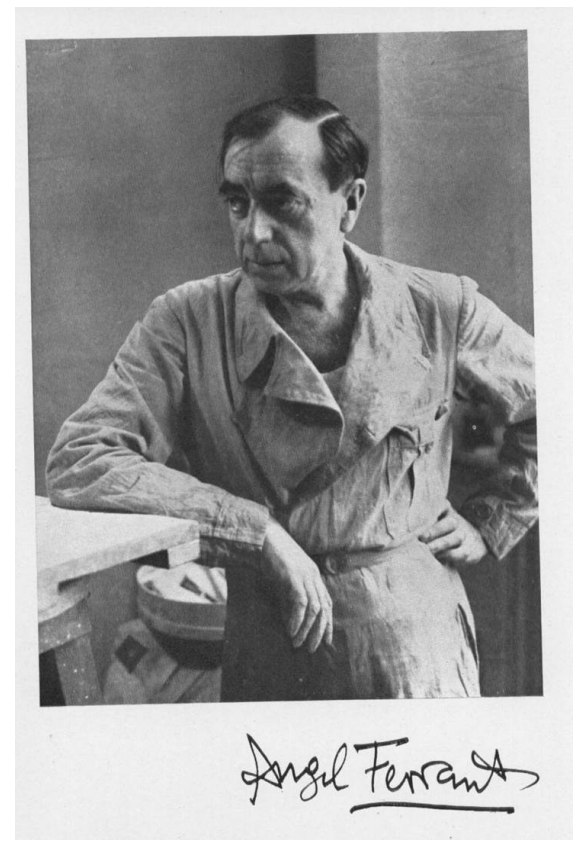

Figura 1. Ángel Ferrant (1890-1961).

\section{Epítome de las influencias}

Durante los años veinte las primeras publicaciones de carácter pedagógico en España sirven para dar a conocer los aspectos esenciales de las nuevas pedagogías, algunas de las cuales son muy populares en Europa. Con estas publicaciones las corrientes pedagógicas más avanzadas dejan de ser meras experiencias para convertirse en paradigmas educativos. Estas corrientes tienen como soporte teorías y modelos explicativos, psicológicos o psicopedagógicos, que dan origen a formulaciones prácticas de carácter general o a concepciones didácticas, metodológicas y organizativas para la educación, en especial la infantil. Ferrant sigue de cerca las corrientes extranjeras más renovadoras en materia de pedagogía y se siente influido por ellas. Su anhelo es aprovechar la influencia foránea y beneficiarse de la obra de los grandes educadores, entre cuyos métodos y los del escultor se puede advertir una afinidad en los principios que los mueven. Si bien se acerca a la poética de su recepción buscando el contenido y el significado de las proposiciones pedagógicas específicas de cada texto, la decisiva influencia que ejerce en él la interpretación educativa de estos escritos se debe en buena medida a su formación cultural y a su bagaje personal. Ambos aspectos son fundamentales para conocer la repercusión de estas influencias. Para que los 
textos alcancen todo su sentido ha de entender los instrumentos manejados por los educadores -sólo así puede vincular los escritos y criterios metodológicos a su personal ideario educativo- y recibir de aquéllos un mensaje como forma. Ferrant percibe así en sus interrelaciones, el contenido, la estructura y el mensaje de los textos, y concibe su función práctica y su valor pedagógico. La complejidad de la interpretación implica un alto grado de subjetividad que está basado en un entramado de ideologías y significaciones que se entrelazan.

Por otra parte, el estudio de los métodos pedagógicos de los grandes educadores permite el asentamiento de las bases del modelo pedagógico ferrantiano, logrando con ello un discurso personal e individualizado. Su visión aperturista de la educación artística se basa en un concepto renovador que, rompiendo con la tradición academicista, se apoya en las influencias de los nuevos pedagogos para poner de manifiesto su preocupación por los problemas didácticos. La gnosis, o "conocimiento revelado", que consecuentemente surge de estas influencias, produce un endeudamiento con sus autores. Sólo individuos sensibles como Ferrant están capacitados para recibir y aprehender esta revelación y, por tanto, para poder legar el conocimiento adquirido. Su visión didáctica resulta tan cautivadora porque es personal y porque impulsa con eficacia la enseñanza del arte.

\section{Paradigmas educativos}

Ferrant estudia y analiza las obras de los grandes pedagogos de su tiempo. La influencia de estas obras es notable y condicionará su trayectoria docente. De sus lecturas extrae un amplio espectro de anotaciones, de las cuales podemos conocer su procedencia gracias a que anota cuidadosamente en cada una el título de la obra consultada, el año de edición y el número de página. En cada volumen busca ciertos órdenes precedentes, que el escultor asimila y desentraña para, posteriormente, equiparar lenta y favorablemente conceptos e ideas, en un proceso de tiempo y experiencia, más o menos dilatado, hasta convertirlos en un proceso de toda una vida. No cabe duda de que las recombinaciones que se producen son resultados de distintos procesos: unos son arbitrarios, sin ningún interés aparente; otros son subjetivos, sin conexión con ideas y conceptos relevantes; algunos son cruzados, que conectan o reúnen las ideas en distintas posiciones; también los hay combinados, con ideas perfectamente integradas en nuevas estructuras con características nuevas; y por último, los hay emergentes, que constituyen un sistema autónomo independiente de la lectura, y generan contextos de interpretación nuevos.

No hay que olvidar el interés de Ángel Ferrant por el arte infantil. El escultor, conocedor de los novedosos métodos educativos y de las premisas que sobre pedagogía experimental se desarrollan en Europa durante los años veinte, siente afinidad con sus teorías, las cuales son ampliamente traducidas en España. Entre sus anotaciones encontramos numerosas transcripciones de su puño y letra de obras de pedagogos tan célebres como las del estadounidense John Dewey (1859-1952), las del psicólogo y pedagogo suizo Édouard Claparède (1873-1940), las de la educadora y médica italiana Maria Montessori (1870-1952), las del filósofo alemán Kart Gross (1861-1946), o las del médico y psicólogo belga Ovide Decroly (1871-1932), entre otros. Algunos 
de los educadores citados asisten en España a los cursos de las Escuelas de Verano, cuya experiencia concreta se lleva a cabo en Cataluña con anterioridad a la Guerra Civil. La Escuela del Mar de la Barceloneta, fundada en 1922, siendo su director Pedro Vergés, es una de las más importantes. La idea fundamental sobre la que se plantea su sistema educativo es la adaptación de la enseñanza a las aptitudes innatas de la psicología infantil.

La influencia que ejercen las obras de estos pedagogos sobre Ferrant es notable. La ideología que manifiestan es indudablemente afín con sus pensamientos. No obstante, una de las filosofías didácticas que más le influye es la planteada en los ideales de la Escuela Activa, la cual sigue atentamente desde sus inicios. Ferrant puede examinar de cerca las bases pedagógicas contenidas en sus textos. Sus anotaciones transcritas proceden de varios manuales de carácter psicológico y pedagógico, si bien son tres los más relevantes. El primero, del pedagogo escocés William Boyd (18741962), profesor de educación en la Universidad de Glasgow, lleva por título "Hacia una nueva educación" (1931); en él se trata la relación y síntesis de los debates sobre la nueva psicología y el programa, expuestos en la quinta conferencia mundial de la Asociación de la Educación Nueva, celebrada en Elsinore (Dinamarca), en agosto de 1929. Los otros dos libros, "La Práctica de la Escuela Activa" (1927) y "Tres Heraldos de la nueva educación" (s.f.), escritos ambos por el educador suizo Adolphe Ferrière (1879-1960), tratan respectivamente de los ideales en que se inspira esta Nueva Escuela y de la labor educativa desarrollada por Hermann Lietz (1868-1919) en Alemania, Giusseppe Lombardo-Radice (1879-1939) en Italia y František Bakule (1877-1957) en la República Checa. A pesar de que las citadas fuentes documentales están vinculadas sobre todo con el arte en la infancia, Ferrant adaptará el contenido de sus pasajes al nivel escolar de sus jóvenes estudiantes de las Escuelas de Artes y Oficios.

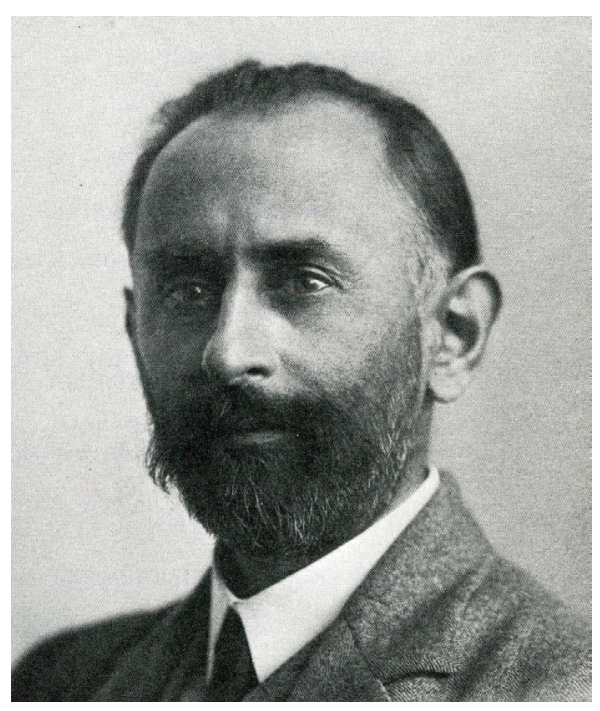

Figura 2. Adolphe Ferrière (1879-1960). 
Uno de los aspectos que más llama la atención a Ferrant del citado libro de Boyd, es la parte relativa a la manifestación creadora, que su autor desarrolla en el capítulo VII. El escultor transcribe en una de sus anotaciones un fragmento que se ocupa de los intereses vitales de los alumnos y de la necesidad de libertar de los obstáculos y limitaciones de los adultos a los niños, apostando por una enseñanza dinámica en la esfera de las valoraciones espirituales:

En el pasado se daba por supuesto ordinariamente que el dominio en las obras de arte [...] estaba tan por encima de las personas vulgares, que la actitud adecuada respecto a ellas -especialmente en la infancia y en la juventud- era la de la humilde y pasiva aceptación. En las lecciones de valoración el alumno podía ser ayudado para gozar y comprender en cierta medida su significación; pero únicamente debía esperar una perspectiva limitada y no soñar, en cualquier obra original suya, con acercarse a la perfección.

$Y$ ahora el nuevo educador que ha estado tratando de mirar a la vida a través de los ojos del niño, llega a desafiar esta paralizadora doctrina de pasiva valoración. Lleno de fe en las energías humanas ha libertado al niño de los obstáculos y limitaciones de los adultos, colocándolo en un ambiente de obras y acciones bellas, y el niño ha llegado a ser un creador por sí mismo. Dándole ocasiones adecuadas, las grandes fuerzas mundiales que se expresan, de cuando en cuando, en los creadores, artistas y videntes, se apoderan del estudiante y, maravilla de las maravillas, éste se produce con gracia perfecta, escribe poesías que ostentan la nota original, actúa bellamente y tiene sus visiones de verdad, bondad y belleza. Una vez más se ha visto que el niño está más cerca del reino de Dios que el adulto. (Boyd, 1931).

A este respecto, en otra de sus anotaciones, Ferrant transcribe las aportaciones pedagógicas del educador checo Bakule. En dicha anotación consta que uno de los logros de este educador es conseguir que cada creación de sus alumnos lleve su sello propio. Dicho resultado satisfactorio lo obtiene despertando y desarrollando las facultades creadoras de cada individuo creador: "No se trata más que de crear la atmósfera favorable, el medio ambiente que despierte las facultades del niño, dándole ocasión de manifestarlas y ponerlas en condiciones de cultivarlas" (Ferrière, s.f.). En este mismo sentido, se desenvuelve también la obra de la educadora italiana María Montessori (1870-1952). Ferrant transcribe un fragmento de su libro "Les Case dei Bambini", citado por Ferrière, en el que pone de manifiesto la necesidad de libertad expresiva:

La piedra de toque de la pedagogía científica debe ser la libertad de los alumnos, absolutamente necesaria para hacer posible el desarrollo de las manifestaciones individuales.

Estimular la vida, dejándola no obstante desenvolverse libremente, es la misión del educador.

Hace falta un gran arte para elegir el momento; mantener su intervención dentro de ciertos límites y no desviar de su camino natural el alma que nace en la vida y que debe vivir por sus propias fuerzas. (Ferrière, 1927). 


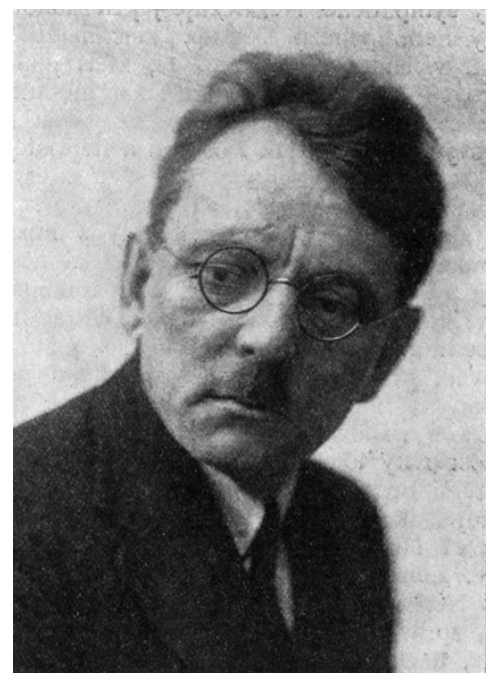

Figura 3. František Bakule (1877-1957).

De acuerdo con Boyd, Bakule y Montessori, Ferrant redactará propuestas didácticas análogas en su plan de reforma "Diseño de una configuración escolar. El Estado y las artes plásticas", también conocido con el nombre de "El pla Ferrant", cuyo contenido se publica en varias ocasiones en 1932 y 1933. En dicho texto formula un plan de estudios, dentro de las Escuelas Federadas de Artes Plásticas del Estado, y varias propuestas concretas para mejorar la formación de los estudiantes de artes plásticas. En su preliminar reseñará la necesidad de organizar centros de enseñanza artística que permitan alcanzar la plenitud de la expresión artística y aprovechar las dotes naturales de la juventud:

El Arte es un recreo del espiritu. Es una forma viva y cambiante que en las sociedades civilizadas no puede producirse normalmente sin un nexo intelectual.

Por lo tanto, si se persigue la plenitud de su expresión, si se pretende aprovechar las dotes naturales de la juventud, bien para llegar a producirlo, bien para llegar a gozarlo y que de ello se deduzca la satisfacción auténtica de nuestras necesidades espirituales, se hace absolutamente necesario organizar centros cuya actuación esté de acuerdo con las aspiraciones contemporáneas más precisas. (Ferrant, 1931).

Otro aspecto importante que Ferrant destaca de Boyd es la relación que establece entre las miras que ha de tener el maestro y el fin de la enseñanza. Según se desprende de una de las anotaciones del escultor, Boyd apunta, por un lado, que lo que los maestros necesitan obtener de los niños es una expresión de personalidad e individualidad única, y por otro, que el fin de la enseñanza no es, naturalmente, producir una obra de arte, sino más bien permitir al niño "elevarse a su máximo de productividad". No cabe duda de que los dos semblantes apuntados por Boyd serán rápidamente acep- 
tados por Ferrant y puestos en práctica no sólo con sus alumnos de Artes y Oficios, sino también con niños. Respecto al interés de Ferrant por el arte infantil, no hay que olvidar que colaborará activamente con la Escuela del Mar de la Barceloneta, antes y después de la Guerra Civil, y que escribirá varios artículos relacionados con el arte en la infancia; además, promocionará, en 1935, distintas iniciativas privadas destinadas a las labores de protección de la infancia y a las actividades de formación para niños de barriadas obreras. Respecto al modo de actuar con sus alumnos de Artes y Oficios, Ferrant pondrá de manifiesto la esencia de su pensamiento docente en una entrevista, concedida en noviembre de 1931 al crítico de arte y periodista Sebastià Gasch:

Yo no soy profesor en la idea de enseñar, sino en la de impulsar. Ya he dicho que el arte no consiste en saber. El arte no se aprende, el arte se aprehende. Se puede indicar el vehículo, y en este sentido, claro es, va implícita una enseñanza que es el del arte por el cual se explica el Arte. Pero incluso en este caso es imposible que la forma se comprenda con independencia de su contenido. (1931).

El influjo del pintor y pedagogo austriaco Franz Cizek (1865-1946) es especialmente importante en Ferrant, principalmente en todo lo relacionado con el arte infantil. El nombre de este educador y sus reflexiones pedagógicas se hallan una y otra vez en las transcripciones de sus lecturas. En 1927 Ferrant conoce personalmente a Cizek en la Kunstgewerbeschule de Viena, uno de los centros más innovadores de enseñanza artística del momento. El escultor recibe una beca de la Junta para la Ampliación de Estudios para estar pensionado tres meses en la capital austriaca. Allí visita varios centros docentes, entre los cuales se encuentra el Kunstgewerbemuseum y la Kunstgewerbeschule. En Viena conoce, entre otros profesores, a Cizek -profesor de Teoría de las formas y de Instrucción artística o Arte Primario- y a Eugen Gustav Steinhof (1880-1952) -profesor de Escultura y Modelado-.Durante su estancia en Viena este último educador es su interlocutor y mediador. Steinhof tiene la amabilidad de dejarle para su estudio algunos trabajos manuscritos acerca de las materias que él y Cizek imparten. Ferrant ocupa parte de su tiempo en Viena estudiando los métodos de enseñanza de ambos docentes. El influjo de Steinhof también es muy importante en Ferrant. Ciertos ejercicios que el profesor austriaco plantea a sus alumnos como, por ejemplo, el levantamiento de vasos en hueco, son análogos a los que Ferrant planteará a sus estudiantes de Artes y Oficios a partir de 1927. No cabe duda de que las aportaciones de los profesores austriacos, las explicaciones de sus teorías y la visualización de los trabajos de sus alumnos dejarán una significativa impronta en el futuro desarrollo pedagógico del profesor español, quien, a su regreso a España, tomará importantes iniciativas para la aplicación de nuevos procedimientos didácticos y redactará el mencionado plan de estudios "Diseño de una configuración escolar". 


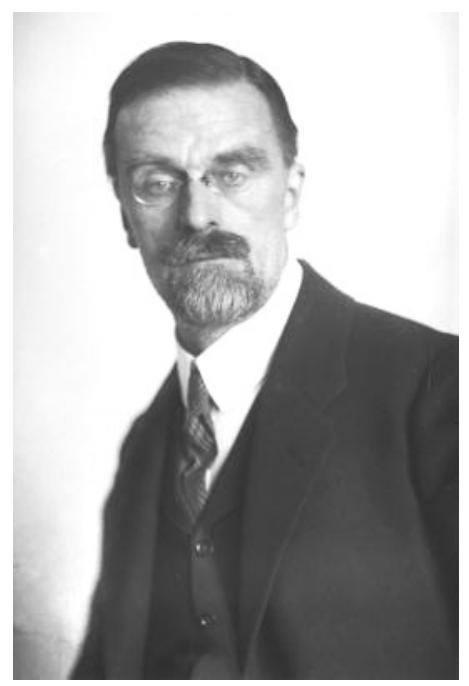

Figura 4. Franz Cizek (1865-1946).

Varias anotaciones de Ferrant aluden a Cizek. Una de ellas, transcrita del citado libro de Boyd, refleja la opinión que sobre el pedagogo austriaco tiene Akad-Maler Albert Gruber (1898-1960), profesor de educación artística en Viena y sustituto de Cizek en sus clases. Según consta en la anotación, el propósito de Cizek es enseñar al niño "el siempre nuevo y vital encanto de la creación". Gruber afirma que éste escoge a los niños singularmente dotados, y que a partir de los 13 o 14 años ya no le interesan, puesto que no se propone trabajar con adolescentes. En su opinión, lo que realmente busca Cizek es "el despertar de lo divino que duerme en el niño".

Ferrière también brinda una especial atención en sus páginas a la labor docente de Cizek. Ferrant transcribe algunos de sus pasajes, en los cuales enuncia varios de sus principios pedagógicos: "la ausencia de coacción e imposición, nada de enseñanza sistemática, ni copias, ni modelos, ni yesos, y, por supuesto, la utilización de gran cantidad de materiales atrayentes de los que pudieran disponer los alumnos a su albedrío en el aula" (Ferrière, 1927). No cabe duda de que algunos de estos principios son manifiestamente análogos a los de Ferrant. En noviembre de 1948 el escultor español enviará una carta al crítico de arte Eduardo Westerdahl, exponiéndole cómo ha de ser para él una escuela experimental de arte:

Una escuela de arte ha de ser, en efecto, un lugar de experimentación. Los comienzos en ella, un verdadero juego -no un pasatiempo- en el que los más diversos materiales o elementos se combinen y se presten a un manejo intuitivo, para obtener resultados en los que el alumno refleje su modo de estimar cualquier fenómeno plástico que le conmueva. Infinidad de procedimientos pueden conducir a las más expresivas producciones [...] No dar la espalda a la imagen óptica de las cosas, sino utilizarla sin concederle, por lo que es en sí misma, el más mínimo valor como obra de arte [...] Los modelos deben proscribirse. Mejor dicho, la palabra "modelo" no debe llamar a la imitación, sino significar uno de tantos utensilios [...] (Ferrant, 1948). 
Otra anotación, del Dr. Paul L. Dengler (1893-1974), Director del Instituto AustroAmericano de Educación en Viena, en los años 30, refleja el sentir de Cizek con respecto a la técnica, la cual considera como el único medio de enseñanza en el pasado, reduciéndola en sus clases a un mero expediente. Según consta en la anotación, lo que Cizek trata de conservar en el niño es su mundo propio, el yo inconsciente con objeto de guardarle contra el influjo destructor del ambiente normal. Según Dengler, Cizek mantiene que tanto la imitación -enemigo que más aborrece- como las ideas adultas desvían la verdadera habilidad del individuo para expresarse:

Cizek asegura que hay dos yos en cada individuo: uno, consciente de su existencia; otro, inconsciente; es el segundo el que pone su sello sobre la obra de arte juvenil y le presta su peculiar encanto. La escuela ordinaria traba y amordaza este yo inconsciente. La habilidad del niño para expresarse en el dibujo viene a ser desviada por las ideas adultas, su individualidad marchitada, y así resulta una desmañada persona sin ningún valor. (Boyd, 1931).

Con respecto a la imitación, Ferrant expondrá ideas similares a sus alumnos de Artes y Oficios, a quienes enseñará el valor de las disposiciones germinales de la creación, sugiriéndoles que las obras artísticas han de brotar siempre de la propia creación, nunca de la copia:

No es lo mismo asimilar que imitar

Y no es lo mismo sensibilidad que maestría

De todas las aberraciones, ninguna lleva a la estupidez como la imitación

Y si la imitación se hace de la maestría, la estupidez llega al infinito. (Pizarra de clase, s.f.).

Dentro de la totalidad del proceso educativo, Gruber señala que "la educación en arte es el corazón del sistema total educativo". Para Ferrant, sin embargo, mucho más importante que la preparación especializada será la educación de carácter general, puesto que, "cuando el trabajo profesional se ve desatendido por la opinión de los no profesionales, el esfuerzo, la obra de aquellos, es destruida por éstos". (Ferrant, 1938).

En otro orden de cosas, las ideas profesadas por la École active, o Escuela Activa, que a partir de 1917 se presenta como sinónimo de Escuela Nueva, también son especialmente importantes en Ferrant $\mathrm{Su}$ concepción de aprendizaje tiene como base el proceso de adquisición individual de conocimientos, de acuerdo con las condiciones personales de cada educando, y bajo la intervención del principio del activismo. La idea fundamental sobre la que se plantea su sistema educativo es la acomodación de la enseñanza a las aptitudes innatas de la psicología infantil. La práctica del aprendizaje se realiza a través de la observación, la investigación, el trabajo y la resolución de situaciones problemáticas, en un ambiente de objetos y acciones prácticas de tipo lúdico, y con ejercicios descriptivos, prácticos o manuales en donde el niño desarrolla activamente su propia educación. Ferrant conoce sobre todo los ideales de la Escuela Activa en el educador suizo Adolphe Ferrière, en quien cobra excepcional importancia la actividad espontánea, personal y productiva. 
La finalidad del acto didáctico está en poner en marcha las energías interiores del educando, respondiendo así a sus predisposiciones e intereses, en un ambiente de respeto, libertad y actividad. En los años 20, Ferrant tiene su residencia en Barcelona, así pues, puede asistir, escuchar y asimilar directamente las ideas y debates de aquellas pedagogías renovadoras. Además, tiene oportunidad de estudiar la obra de Ferrière, y de seleccionar de entre sus páginas numerosas anotaciones, ya que buena parte de sus libros son traducidos al castellano. Una de estas anotaciones permite examinar las apreciaciones didácticas de Ferrière sobre el empleo de la técnica. El pedagogo suizo entiende que ésta se ha de utilizar con mesura y siempre que el individuo la desea, ya que de lo contrario puede ocasionar daños perniciosos en su posterior desarrollo artístico:

En el comienzo, la técnica debe ser comprendida y deseada por el niño; si no la desea, esto significa que el niño es todavía muy joven para comprender la necesidad de esta técnica, y si entonces se la imponemos, le haremos tomar repulsión por ella, por lo cual producimos un grave retraso en la adquisición eficaz de esta técnica, y por tanto el correspondiente retraso para la utilización de la misma en los ejercicios de la expresión espontánea y creadora; retraso o supresión pues hay gustos nacientes que ahogados en flor no renacen nunca. (Ferrière, 1927).

Ferrant también concederá importancia a la técnica. En su opinión, antiguamente era inevitable que la técnica propiamente mecánica apareciera mezclada y confundida a la técnica propiamente manual: "Hoy, en cambio, la mecánica realiza una gran parte del trabajo que antes hacía la mano; por lo que, en el presente la técnica nos ofrece sus direcciones, mejor dicho, sus posibilidades, con mayor claridad" (1931). A este respecto, en el catálogo de la exposición antológica de Ángel Ferrant, celebrada en Madrid, en 1983, José Romero Escassi (1914-1994) apunta que, en la Escuela de Artes y Oficios de la calle del Marqués de Cubas, recibe el magisterio de Ferrant como algo insólito hasta entonces en su personal experiencia (El nombre de José Romero Escassi no aparece en los registros de alumnos de la Escuela de Artes y Oficios de Madrid, sección 2a en ningún curso académico. Quizá asistió a las clases de Ferrant como alumno oyente). Señala que en sus clases se discrimina con plena lucidez, por parte del maestro, lo que pertenece al dominio técnico y es por tanto motivo de disciplina instrumental, de aquello que es de potestad individual y creativa:

En ningún momento se confundía, como tantas veces sucede en otras partes, la auténtica libertad creativa con el capricho azaroso ni el aprendizaje técnico se convertiría nunca en rutina manual. Cada ejercicio propuesto por el maestro suponía algo así como acotar un espacio de labor con límites perfectamente definidos y con intenciones claramente explicadas previamente, quedando, por supuesto, dentro de aquellas normas una holgura suficiente para que la conducta individual pudiera manifestarse. Sus razonamientos eran concisos y de poco bagaje erudito, para desterrar todo énfasis artificioso en su relación con el alumno que pudiera redundar en una obra insincera y afectada. (Romero Escassi, 1983).

Para Ferrant, la imaginación es el verdadero motor de la creación, la técnica no es más que un asistente de aquélla. A este respecto, en una de sus anotaciones 
transcribe las opiniones del Dr. Harold Rugg (1886-1960), profesor de Educación en el Teachers Collage, New York City, disertando en Kronborg Castle sobre "Un programa creador". Bajo su dirección se manifiesta un cambio significativo en el método de las artes:

El maestro artista no impone técnicas demasiado temprano; se mantiene vigilante detrás del niño esperando que éste se revele por sí mismo, tratando de hallar lo que hay en esta personalidad única. (Ferrière, 1927).

Rugg diferencia los métodos utilizados por el científico y por el artista. El primero tiende a la producción, normalización y uniformidad, el segundo da importancia al concepto de singularidad. Según este autor, los educadores en arte, "sin perder de vista el propósito espiritual, la intuición del artista y la técnica del científico, producirán un programa de actividades y materias que consumarán estos dos grandes fines", lo cual habrá de ir acompañado de la experiencia personal. A este respecto, Ferrant expondrá a sus alumnos: "Para llegar a copiar bien se requiere mucha atención. Para llegar a producir formas nuevas hay que ejercitar la imaginación" (Pizarra de clase, s.f.). Así, parafraseando a Ferrière, se podrá decir: "yo sé, porque he experimentado".

Otro de los aspectos más destacados de la didáctica de Ferrant es la importancia que concede a la figura del artista-profesor, al que considera un "elemento indispensable" dentro de la enseñanza general. De sus anotaciones destacan no sólo las del educador checo Bakule, el cual opina que "los artistas educadores harían nacer energías creadoras en tan gran número de individuos, que colmarían ampliamente los vacíos producidos en las distintas ramas de actividad" (Ferrière, s.f.), sino también las de Gruber, quien considera que el profesor de arte necesita trabajar en su propia obra para poder comunicar el placer de la creación:

Es también esencial que solamente el artista activo -el pintor, el escultor- pueda enseñar en las escuelas superiores. El profesor de arte necesita trabajar él mismo, pues únicamente entonces puede comunicar a sus alumnos el placer de la creación y mantener al joven como creador entre creadores. El artista que trabaja es de suponer que domina todas aquellas posibilidades de asunto y técnica que elevan al niño mal dotado a despecho de sí mismo. (Boyd, 1931).

Ferrant, por su parte, dedicará una sección a la figura del artista-profesor en su plan de reforma de las Escuelas Superiores de Bellas Artes, redactado en 1938 y titulado "La educación en arte y sus tangencias con la enseñanza general".

Ferrant, convertido por entonces en portavoz de la moderna pedagogía artística en España, forma parte activa de la Comisión de expertos del Consejo Central de Artes Plásticas que el gobierno de la Segunda República española crea, en plena Guerra Civil, con el fin de reorganizar las enseñanzas artísticas y la Escuela de Arquitectura. Ferrant es el encargado de redactar el proyecto destinado a la reorganización de la Escuela de Bellas Artes. En el mismo, no estudia de forma aislada este Centro educativo, sino que, más bien, vincula los estudios de Bellas Artes a otras disciplinas artísticas y educativas (Asenjo, 2009). 
En dicho documento apuntará que para que profesor y artista puedan comprenderse y caminar juntos, habrán de cruzarse sus ideas:

Artista y profesor son términos que, al parecer se contradicen. Indudablemente corresponden a dos tipos de hombre. El artista sigue siendo el hombre de ayer; es el rezagado, el divo, el inconsciente. La corriente del mundo no le arrastra, le azota. El profesor, por el contrario, consciente de su misión y activo, siéntese empujado por la ciencia, e incorporado a la juventud -al mañana- a la que anima; y marcha hacia un fin concreto al ritmo de su tiempo. (Ferrant, 1938).

No obstante, Ferrant aclarará que no hay que pensar que de los artistas por sí solos, pueda surgir inmediatamente el profesorado de calidad que se necesita: "Habría que formar esos profesores". Considerará que si los profesores de su tiempo hubieran recibido instrucciones de artistas profesores, los artistas de su tiempo estarían en condiciones de, en un momento dado, convertirse fácilmente en artistas-profesores: "Pero, el artista, si está desplazado en la sociedad actual, es porque carece de los principios científicos que le liguen a ella sin separarle del sentido del vivir que le es consustancial". (Ferrant, 1938).

Por otra parte, en la amplia serie de anotaciones y citas que Ferrant extrae de sus lecturas, encontramos algunas relacionadas con el deleite artístico. En una de ellas, Gruber cuestiona aspectos como la posibilidad efectiva de crear artistas y la de educar para el arte. En relación con la dualidad arte-educación, el educador austriaco pregunta: “¿se puede crear artistas con la educación? No. ¿Se puede educar para el arte? ¡Sí!. Todos los niños, aun los mal dotados, pueden participar del goce artístico en tareas llevadas a un éxito satisfactorio" (Ferrière, 1927). El propósito de Gruber no es hacer artistas, sino enamorados del arte, "personalidades perfeccionadas por ser la satisfacción de sus propias creaciones". Dicha enseñanza se basa en el principio de aprovechar el momento oportuno, lo cual es posible sólo con un programa amplio y flexible. En su opinión, el maestro necesita tener libertad para utilizar de inmediato "cualquier fuerte impresión de los muchachos y fijarla, dándole forma". Así, en palabras de Gruber: "la enseñanza actual consistirá únicamente en el goce que proporciona el hacer". Además, el profesor austriaco afirma que no hay nadie tan poco capacitado que no pueda desarrollarse, disfrutando del goce que el arte produce:

El artista maestro, si realmente trabaja con fuerza en su propio estudio, tiene a su disposición innumerables asuntos que solamente tiene que ensayar uno tras otro con el niño peor dotado, hasta llegar al fin a uno que despierte su interés, y hacerle creer que él puede conseguir algo en ello. La alegría y afán con que cae sobre esta parte de trabajo creador que está a su alcance ha determinado en cientos de casos el desarrollo de una aptitud para otras formas de arte. (Ferrière, 1927).

Asimismo, en las anotaciones de Ferrant hallamos transcritas las ideas que otros educadores exponen sobre el aprendizaje y el deleite artístico. Así, para Bakule, aprender no es nada más que un fácil juego que procura una agradable distracción; para Claparède, "el secreto está en disponer las cosas de modo que el niño se sienta atraído hacia ocupaciones (juegos o trabajos, poco importa el nombre, con tal que 
susciten el esfuerzo y sean educativos) que estimulen su desarrollo intelectual, moral y social; en resumen, que todo lo que quieran sea un motivo de progreso" (Ferrière, 1927). A este respecto, el profesor español expresará: "El sentir no es el saber. Aquí, únicamente nos proponemos saber donde está lo que sentimos". (Pizarra de clase, s.f.).

Por otra parte, entre las anotaciones de Ferrant encontramos referencias sobre otra de sus preocupaciones didácticas: la dualidad razón-intuición. En una de estas anotaciones transcribe las ideas del senador Albrecht Leo Merz (1884-1967), fundador y Director de la Werkschule, en Stuttgart, Alemania. Merz apunta que las facultades intelectuales e intuitivas necesitan ser desarrolladas juntas e igualmente, así la unidad de la vida escolar únicamente puede ser conseguida considerando la enseñanza desde el punto de vista del artista, "que ve su cuadro como un todo" (Boyd, 1931). En otro apunte, tomado del libro de Ferrière "Tres Heraldos de la nueva educación", Ferrant transcribe algunas de las tesis del pedagogo italiano Giusseppe Lombardo-Radice, Director de Enseñanza Pública y legislador escolar en 1923. Una de ellas hace referencia a la prescripción del dibujo libre en los niños, como medio de expresión y de iniciación al arte; otra se refiere, poniéndose de acuerdo con Benedetto Croce, a la "intuición expresión", es decir, "la realización del Yo en lo que hay de más profundo, en su orientación espontánea hacia lo que hay de más alto" (Ferrière, s.f.). Otra de las tesis del autor italiano es la de la teoría de la identidad de valor, en el lenguaje, o modos de expresión de las palabras y de los signos y, por consiguiente, perfecta coincidencia de las relaciones didácticas del lenguaje y del dibujo:

El dibujo espontáneo es elevado al grado de tarea fundamental del niño. El trabajo manual considerado como plástico y construcción espontánea, excluyendo todo formalismo [...] ;Todo niño es poeta, pintor, escultor, cantor, potencialmente sabio, teólogo y hasta filósofo (claro... infantil) y todo cuanto quiera a la manera de niño! (Ferrière, s.f.).

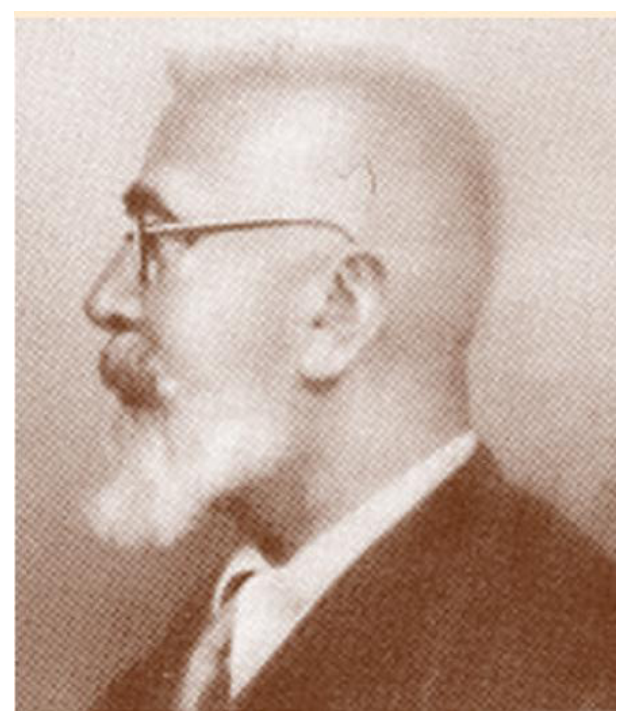

Figura 5. Giusseppe Lombardo-Radice (1879-1939). 
Ferrant, por su parte, también considerará que el binomio razón-intuición es parte inseparable del proceso artístico. Concretamente, en su plan de reforma "Diseño de una configuración escolar", arriba citado, señalará que conviene aspirar a una conciencia intelectual partiendo de las dotes individuales del estudiante:

A la escuela corresponde por vía doctrinal y práctica incorporar a lo que es temperamento todo cuanto en la imaginación y en el intelecto puede dar origen a la materialización más depurada.

Se ha partido de la intuición y se ha de llegar al conocimiento. Imposible obtener resultados afirmativos procediendo al contrario, como se vino haciendo. (Ferrant, 1931).

Siguiendo esa dirección, Ferrant transcribe en otra de sus anotaciones una cita de Ferrière en la que enuncia las tres etapas del devenir social: "autoridad consentida, anarquía relativa y libertad reflexiva" (Ferrière, 1927). Por su parte, el escultor español programará, en su plan de estudios de 1931, anteriormente citado, tres fases del alumno en la escuela:

$1^{\circ}$ Libre manifestación, de carácter general, de las dotes naturales con que el escolar vino al mundo.

$2^{\circ}$ Cultivo de esas dotes individuales mediante una actuación cada vez más consciente e intelectual por parte del alumno y profesores.

$3^{\circ}$ Instrucción cientifica especial y realizaciones definitivas. (Ferrant, 1931).

Entre los papeles del escultor encontramos otra serie de anotaciones que transcriben los pensamientos del profesor Gruber con respecto al papel que ha de asumir el docente frente a la obra de sus alumnos. El profesor austriaco rechaza que el maestro ponga sus manos en el trabajo de sus alumnos; sostiene, no obstante, que el trabajo se someta a una estrecha crítica:

En todo ello el maestro se mantendrá aparte; sostendrá el entusiasmo, observará el choque de opiniones diversas, aclarará un punto aqui y allá y registrará los hechos establecidos. Si toma una parte más activa, únicamente conseguirá amortiguar el entusiasmo de los niños. Claro que necesita discutir varias cosas con sus alumnos; no puede dejar que crezcan como plantas silvestres. Los niños esperan su auxilio y dan por supuesto que lo conseguirán. El maestro sabe si debe ayudarles o si debe dejar que ellos resuelvan su problema por sí mismos. Unas pocas palabras sacadas de la experiencia del trabajo propio bastan generalmente para avivar un interés que languidece [...] El alumno necesita acudir al maestro en demanda de ayuda, éste no debe proponerla. Cuando esto ocurre, el maestro verá si la mayoría de la clase ha alcanzado el punto en que estos aspectos más precisos del arte ha empezado a interesarles, y si es así, debe poner las cosas en movimiento y no debe desalentarse si, después de todo ello, encuentra que ha sido incapaz de ayudar a algunos de sus alumnos. Necesita tener paciencia hasta que ellos lleguen al punto en que puedan aprovechar sus servicios. (Ferrière, 1927).

Ferrant, por su parte, tampoco intervendrá con sus manos en los trabajos de los alumnos. Así lo recuerda José Romero Escassi en el catálogo de la exposición antológica de Ángel Ferrant del año 1983: "Nunca intervenía con sus manos en los 
trabajos en curso; comentaba, sugería, pero jamás dictaba una solución que pudiera equivaler a una receta infalible" (R. Escassi, 1983). Gruber apunta que este género de enseñanza no es tan cómoda como la que prepara para exámenes, "pero es más humana, y se ve rodeada de rostros brillantes y risueños". Ferrant se sentirá vinculado a los objetivos fijados por Gruber, los cuales son claramente afines con los principios del institucionismo (Asenjo, 2004).

Con respecto a los jóvenes que no pierden la encantadora indiferencia del niño, la experiencia de Gruber prueba que comúnmente aquéllos no sólo llevan consigo su alegría infantil en el trabajo, sino que conservan algo de la facultad creadora de la infancia. Gruber apunta que el alumno que está perdiendo la encantadora indiferencia del niño, poco a poco empieza a descubrir lo inadecuado de sus propios esfuerzos comparados con los del adulto. En su opinión, este sentimiento de disgusto puede reducirse a un mínimo "si su vida inconsciente y sus manifestaciones le han sido hechas previamente comprensibles, y si ha sido llevado gradualmente a reproducir en su arte el mundo de la imaginación" (Ferrière, 1927). Gruber pregunta por qué se permite que desaparezca la alegría de las experiencias de los niños en el ejercicio de su facultad creadora conforme aquellos se acercan a la adolescencia, a lo cual responde:

Si los maestros fomentan la individualidad de cada alumno, si mantienen vivo el interés del niño en el adolescente, todos alcanzarán aquel goce puro del arte que conduce a la belleza en la vida gris cotidiana. (Ferrière, 1927).

Ferrant al igual que Gruber, con quien compartirá la idea de fomentar la individualidad, considerará que el don innato del arte ha de cultivarse a tiempo, ya que de lo contrario se atrofiará:

Muchas personas se manifiestan indiferentes al arte porque carecen del sentido que se necesita para interesarse por lo bello y gozarlo. Quizá vinieran ya al mundo con esa falta como quien nace ciego o mudo. Es posible también que ese don innato se les atrofiara por no haberlo cultivado a tiempo. El caso es que esas personas no tienen derecho a opinar en nuestras cuestiones. (Pizarra de clase, s.f.).

Otra anotación de Ferrant transcribe las experiencias de O. Wommelsdorff, miembro de la Asociación de Maestros de Hamburgo, relativas a la influencia de los trabajos colectivos en el desarrollo de la forma artística entre los niños de la clase pobre:

Entre los pequeños de 6 á 9 años de las clases más pobres, el dibujo y el modelado eran las ocupaciones favoritas, dando muchas veces lugar a nuevos juego [...] Construyendo caretas, dos o tres niños que trabajaban juntos arrastraron a toda la clase a su colaboración, confeccionando y pintando, criticando y ensayando, y elaborando por sí mismos satisfactoriamente un método en la fabricación de caretas". (Ferrière, 1927).

En este mismo sentido, cabe mencionar otra anotación, que Ferrant transcribe del libro "La práctica de la Escuela Activa", de Adolphe Ferrière, según la cual Cizek 
observa que "los niños pobres hacen mejores cosas que los niños ricos a causa de tener sus facultades menos deformadas por la memoria y la imitación" (Ferrière, 1927). Ferrant, por su parte, afirmará también que los jóvenes especialmente instruidos y más habituados a las actividades corrientes de la sociedad, son los más incapacitados para el arte, al contrario que los muchachos incultos. Así lo expresará en la mencionada carta que escribe a Westerdahl en 1948: "un muchacho inculto, desconectado o de rara mentalidad es más probable que dé mejor fruto"(Ferrant, 1948).

\section{Conclusiones}

Una visión general de los paradigmas educativos actuales, tanto en el ámbito psicológico, personal y estructural, permite comprobar cómo en educación artística se ha mejorado y han ido cambiando las perspectivas en cada época. En algunos casos se puede observar cómo algunas prácticas docentes planteadas por Ferrant se mantienen vigentes a pesar de la globalización y los cambios vertiginosos en el mundo de la información y las competencias que ésta exige. Ejemplo de ello es el paradigma personalista o humanista, que propone que un "buen profesor es como un artista habilidoso capaz de facilitar el desarrollo personal del alumno"; dicho modelo está regido por el criterio de que la enseñanza es básicamente un proceso de desarrollo y relación interpersonal. De la misma manera se mantiene vigente el paradigma críticoreflexivo, cuya aspiración a mejorar el mundo a través de la educación artística permite establecer una conexión entre la formación académico-cultural y la realidad social exterior. Por su parte el paradigma conductista, cuyo criterio fundamental de la eficiencia docente es el desarrollo de aptitudes y conocimientos de los alumnos, medidos antes y después de la influencia del profesor, no se corresponde con el modelo ferrantiano. Asimismo, tampoco se corresponde el paradigma culturalista o racionalista, que ve el aprendizaje de la enseñanza artística como un proceso de modelado en que el alumno aprendiz imita al maestro. No obstante, en la actualidad existe una tendencia marcada hacia un mayor empleo del modelo crítico reflexivo al acentuar la importancia de las potencialidades que reviste un proceso de formación intelectual y analítica. En este sentido, la distinción "gnosis" frente a "técnica", manejada por Ferrant, no siempre es compatible con los actuales paradigmas pedagógicos y artísticos. Un artista-profesor del siglo XXI está obligado a conocer, dominar y aplicar la teoría artístico-educativa siendo un agente transformador del ser humano en sociedad, del mundo globalizado y de las exigencias de la sociedad cultura, tecnológica, artística y educativa.

Como colofón de todo lo expuesto, es posible afirmar que Ferrant oscila entre la pedagogía, la psicología y la biología. Su visión de la pedagogía artística va más allá de la instrucción, se trata de entender la educación en arte como una ciencia que ayuda al sujeto a canalizar sus emociones a través de la expresión artística. Ferrant es consciente de que la teoría de la educación artística está tan sujeta al análisis y a la crítica como una teoría científica, y para que sea aceptable debe quedar abierta a la posibilidad de ser refutada sobre la base de argumentos razonados. Sabe que detrás de cada experiencia en educación existen unos principios que constituyen las conclusiones prácticas de cualquier teoría educativa. No es ajeno a la influencia de las 
corrientes y tendencias pedagógicas más importantes de su tiempo. Tras la asimilación de estas corrientes, comienza a desentrañar las bases en que se apoyan sus escritos sobre la reforma de la enseñanza artística y sus prácticas educativas. Con todo ello podemos afirmar que muchas de las propuestas pedagógicas, que tienen su origen en los autores arriba reseñados, constituyen el ideario pedagógico del escultor. Sin embargo, pese a que Ferrant ejerce su magisterio durante cuatro décadas en distintas Escuelas de Artes y Oficios -La Coruña, Barcelona y Madrid- en las que ocupa la cátedra de Modelado y Vaciado, su faceta docente ha sido fatalmente ignorada durante años. Consecuentemente, no es posible hablar de la posibilidad de implementación de sus conceptos y modelos didácticos en la actualidad, ni de la vigencia de sus modelos pedagógicos en generaciones de artistas-formadores posteriores. Aunque esto no es cierto del todo, ya que, sin haber llegado a conocer a Ferrant personalmente sí estoy muy unido a él (no en vano imparto clases en la misma aula que Ferrant lo hizo en su momento y envuelto en todo su legado pedagógico), lo considero mi maestro, y la práctica totalidad de sus teorías han guiado, guían y guiarán mi labor docente: tal vez hay lugar para la esperanza.

\section{Referencias}

Asenjo, I. 2004: Ángel Ferrant y los ideales institucionistas, Boletín de la Institución Libre de enseñanza, (56), 95-108.

Asenjo, I. 2007: Ángel Ferrant. La renovación de la enseñanza artística, Arte, Individuo y Sociedad, (19), 7-36.

Asenjo, I. 2009: Los comienzos docentes de Ángel Ferrant: una vocación temprana, Arte, Individuo y Sociedad, (21), 7-26.

Asenjo, I. 2009: Ángel Ferrant y la reforma de las Escuelas Superiores de Bellas Artes, Archivo Español de Arte, LXXXII (325), 47-62.

Boyd, W. 1931: Hacia una nueva educación, Madrid, Espasa Calpe (Trad. L. G. del Arroyo).

Ferrière, A. 1927: La Práctica de la Escuela Activa, Madrid, Francisco Beltrán.

Ferrière, A. (s.f.): Tres Heraldos de la nueva educación. Hermann Lietz, Giusseppe Lombardo-Radice y František Bakule, Barcelona, Publicaciones de la Fraternidad Internacional de Educación.

Gasch, S. 1931: L'ensenyament artistic. Parlant amb Ángel Ferrant, Mirador, (19nov.) Barcelona, 7.

Romero Escassi, J. 1983: El maestro Ángel Ferrant. En Ángel Ferrant [cat.], Ministerio de Cultura (págs. 107-109) Madrid.

\section{Documentos citados}

Documentación de la beca concedida a Ángel Ferrant con destino Viena, en 1927 [Archivo J.A.E, Expediente 54-258, F-32].

Ferrant, Á. 1931: Diseño de una configuración escolar. El Estado y las artes plásticas. [Museo Patio Herreriano, Colección Arte Contemporáneo, Fondo Ángel Ferrant (F. F. - TEX Fe 1-735)]. 
Ferrant, Á. 1938: La educación en arte y sus tangencias con la enseñanza general. [Museo Patio Herreriano, Colección Arte Contemporáneo, Fondo Ángel Ferrant (F. F.- TEX. Fe. 1 - 736)].

Ferrant, Á. 1948: ¿Cómo ha de ser una escuela experimental de arte?, Archivo Histórico Provincial de Santa Cruz de Tenerife, Fondo Westerdahl, D331.

Ferrant, Á. (s.f): Anotaciones del libro "La Escuela Activa I". Museo Patio Herreriano, Colección Arte Contemporáneo, Fondo Ángel Ferrant (F.F. - NOT 45 - 863)].

Ferrant, Á. (s.f): Anotaciones del libro "Tres heraldos de la nueva educación”. Museo Patio Herreriano, Colección Arte Contemporáneo, Fondo Ángel Ferrant (F.F. NOT $4-875)]$.

Ferrant, Á. (s.f): Anotaciones del libro "La ley biogenética y la Escuela Activa". Museo Patio Herreriano, Colección Arte Contemporáneo, Fondo Ángel Ferrant (F.F. - NOT 5 - 876)].

Ferrant, Á. (s.f): Anotaciones del libro "Hacia una nueva educación". Museo Patio Herreriano, Colección Arte Contemporáneo, Fondo Ángel Ferrant (F.F. - NOT $6-877]]$.

Ferrant, Á. (s.f): Anotaciones del libro “La Escuela Activa II". Museo Patio Herreriano, Colección Arte Contemporáneo, Fondo Ángel Ferrant (F.F. - NOT 13- 884)].

Ferrant, Á. (s.f): Anotaciones del libro "Psicología pedagógica". Museo Patio Herreriano, Colección Arte Contemporáneo, Fondo Ángel Ferrant (F.F. - NOT 38-856)]. 